\title{
Digital Prototyping and Augmented Reality Models for Studies of Architectural Design
}

\section{Arne Riekstins}

University of Monterrey, Division of Art, Architecture and Design (DAAD), Av. Ignacio Morones Prieto 4500 Pte., 66238 San Pedro Garza García, Nuevo Leon, Mexico

\section{Corresponding author: arne.riekstins@udem.edu}

\section{$\Gamma$} crossef http://dx.doi.org/10.5755/j01.sace.22.1.21255

The communication of an architectural design project by default is the selling point of any idea when it is being presented to the clients. The use of advanced digital prototyping and virtual 3D models can facilitate the process of presentation significantly, because these technologies allow understanding features that are hard or impossible to present in drawings or pure renderings. CAD/CAM paradigm has set new standards in the field of teaching architectural design, as the contemporary practice has raised the demands for standard skillset expected from future architects once they graduate and enter the design offices. Digital systems that allow designing directly for manufacturing has returned the production and responsibility for giving engineering solutions back to architects. And parametricism in contemporary academic environment is one of the main driving forces of architecture that exercises the exploration of complexity, possible only through 3D modeling tools. Therefore the use of technology in representing complex ideas becomes a standard procedure.

The author explores the implementation of physical and virtual models in architectural design curriculum CNC and rapid prototyping or pure virtual models in format of augmented reality experience. Despite the time-intense learning curve of the additional specific tools and methods involved, there are more advantages to support the efforts of implementing new workflows in the studies of architectural design in as early stage as possible. Students who mastered these skills were able to reach better understanding of tangible and more logical structures in the way they conceptualized, and demonstrated to have more advanced 3D thinking and independence on making formal decisions. Both the physical and virtual models have their own strengths and weaknesses and neither one of them will totally eliminate the necessity of usage of each other.

Keywords: architectural design, augmented reality, CAD/CAM paradigm, prototyping.

Studying architectural design always cover wide field of knowledge from concepts to executive building details. There are several ways of representing the final design in traditional methods by architectural drawings (plans, facades and sections), renderings and scale models. The model making has been long time one of the most laborious tasks, as it implies to represent the design in full 3 dimensions, maintaining a certain scale aspect. The model making has been automatized with the advance of digital fabrication and prototyping, while the precision and new technologies have facilitated to reduce the time and costs associated to the process. New hybrid materials and developments in robotics have increased the possible scale of models, making the full 1:1 scale prototyping viable for making larger building components for later assembly or printing an entire house in 3D directly from design files, as it is manifested by CAD/CAM paradigm - to bring Com-

\section{Introduction}

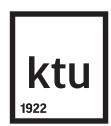

Journal of Sustainable Architecture and Civil Engineering Vol. 1 / No. 22 / 2018 pp. $5-10$

DOI 10.5755/j01.sace.22.1.21255 (c) Kaunas University of Technology 
puter Aided Design straight to Computer Aided Manufacturing. Because technology develops it continuously gives architects new possibilities and sets new challenges.

One of the pioneering augmented reality (AR) applications were discussed more than 20 years ago by Starner et al. (1997), stating that wearable computing is moving computation from desktop to the user, while a new community of networked, wearable-computer users can explore seamless interaction between the virtual and physical environments. Last decade has finally brought to the masses great hand-held devices in form of smartphones and tablets with good quality displays and cameras that can represent models in a more interactive virtual way through the AR tools that can significantly reduce the costs on model making and in several cases even replace physical models as a paradigm. Nevertheless there are certain advantages and disadvantages of this new AR technology that will be discussed further in this article through several applications in various architectural design-related academic studios.

To compare and analyze the application of physical vs. AR models author integrated them in two different architectural design studio setups, one method per semester at University of Monterrey in Mexico. The application of digital prototyping was carried out in a studio of Integral architectural design taught at $4^{\text {th }}$ study year of undergraduate architecture program where the task involved designing kindergarten, church or an art-café. During the entire 16-week semester there were two different physical prototype assignments - to make a structural detail model and to make a 3D printed scale model of the entire volume to complement the final project presentation. The application of AR was integrated in a studio of Architectural interior design taught at $5^{\text {th }}$ study year, where during the semester students were making three different small projects and to present them - each project had a virtual model instead of a physical model. These two studio setups allowed comparing the features and pointing out several strengths and weaknesses of physical vs. AR models.

In the communication of design ideas from architects to engineers and builders the usual format of traditional architectural drawings are mostly limited to two-dimensional sketches. While that is more than enough in a construction environment to understand and build the project, there are plenty of situations where an actual three-dimensional scale model is needed - presenting it to clients, investors, society, exhibiting etc. And the presentation of the model can also be virtual and in a form of an AR application.

Model making distinguishes two fundamentally different techniques where the material is either cut out or 3D printed by adding the material layer by layer. In architectural design schools internationally both of the computerized methods are being used extensively and it is definitely replacing the manual model making by the usage of hand tools. Small laser cutters and desk size 3D printers do the job in an excellent quality and the fabrication costs have become very accessible in the last two decades. Usually the architectural prototypes are being made in 1:500 scale for urban or landscaping projects, in 1:200 and 1:100 scale for building architecture and in 1:50 for interior architecture or smaller projects like mini houses that can show lots of detail. Further the 1:25, 1:20, $1: 10$ and 1:5 scale is more used to represent detail models of specific parts or structural components. Full 1:1 prototyping in academic use is more rarely executed, as increasing up to full scale has much more material and structural engineering challenges to model making, so very often the 1:1 scale is being obtained by subdividing the object into smaller elements or assembly components, that are being assembled at the final stage. As for the academic research, these projects usually are small pavilions or temporary installations made of less time-resistant materials like MDF, triply, wood, all sorts of plastics and light metals.

Prototyping in 1:1 scale has become reality due to advent of recent robotic technologies that extend the abilities of common Computer Numeric Control (CNC) machinery meanwhile providing more effectiveness in the fabrication speed and complexity. The robots set new boundaries of research and act as an accelerator for creativity of the design processes. Automation of design and manufacturing 
allows constant development of new shapes and forms that can be inheriting the latest know-how of sustainability and thus reach the highest economy of material usage or even support a total zero waste fabrication. The most feasible increase of scale in fabrication has brought us to reach the full 1:1 architectural scale by using ultra-high performance concrete in large-scale 3D printers that work with an additive manufacturing (AM) technique. Year 2017 brought to us world's first 3D printed concrete bridge for the cyclists in the town of Gemert in Netherlands. Work on printing the bridge, which has some 800 layers, took about three months and it is made of reinforced, pre-stressed concrete, according to the Eindhoven University of Technology (TG 2017). Several full-scale houses have been 3D printed as well - in 2016 in Beijing's Tongzhou District (Wheatstone 2016), 2018 in Austin, Texas (Badalge 2018) and in Nantes, France (Drury 2018).

Original first prototypes of AR applications were big mobile wearable devices, where the user would basically carry around a backpack with the whole setup that includes a notebook computer, variety of sensors and peripheral devices, while the graphical augmentations were usually shown through an optical see-through head-mounted display (Wagner et al. 2005). With such limitations as the heavy weight, comfortable wearability or looking inadequate in terms of social context, these setups were more appropriate for a laboratory level applications. Further on AR has found its use in all sorts of simulations, including industrial use, info systems, navigation and the world of entertainment through immersive games.

Currently AR models are relatively easy to create out of an existing 3D modeled project in Sketch Up, Rhinoceros, 3DS Max, Autodesk Maya and many other software. Typically the model is being exported to an OBJ extension format (3D object) file with an additional MTL extension file (Materials and textures library), further it is uploaded straight to the mobile device or uploaded online to a secondary processing program that makes the model available through its own native application. To visualize the model in AR it is enough to point the mobile devices camera to an empty surface or special marker and it appears in the given space. The benefit of a specific location based marker is that the model can be handled similarly to a physical model - you can hold the marker in one hand and handle it as a physical model rotating it around and seeing it from closer or further distance. In the academic application AR Player and Augment apps showed the best compatibility and were chosen because of great functionality and easy learning curve to use them.

First physical model application was carried out in a studio of Integral architectural design to address the structural details of geometrically advanced architectural objects. The 3D modeling software applied in the studio was Autodesk Maya or Rhinoceros, both of them being very powerful tools for freeform and non-orthogonal designs to be explored. The freedom of shape and form was a precondition to designing unique constructive and structural details that at the $2^{\text {nd }}$ midterm had to be presented in scale models of 1:20 up to 1:5 scales. To understand the logics of conceptual vs. real building situation, all of the studio models had to be made using a 2-dimensional cutting method of flat or paneled wooden or MDF materials. This involved unrolling any 3D rotated pieces down flat for the cutting layouts, and any irregular geometry had to be proliferated to be composed of 2D planar elements only. The actual model size was limited to a base of $40 \times 40$ $\mathrm{cm}$. Some authors were concentrating in revealing the structural details that connect slab to the facades (see Fig. 1) while others studied the exoskeleton shells and their ribbed connections (see Fig. 2). In almost all of the cases this exercise helped finding more optimal constructive solutions and elements that needed to be improved.

The second physical scale model was already at the end of the semester to present the entire project in the final presentation. Precondition for these models were to use high-resolution industrial level 3D printers available at the laboratory of digital fabrication at University of Monterrey. After few small 3D print tests and the given 3D printer accuracy to render the models in 0.1 $\mathrm{mm}$ precision, it was decided that every model shall be made in 1:200 scale where most small 
Fig. 1

Structural detail model in 1:10 scale laser-cut and assembled of parts from plywood and balsa wood

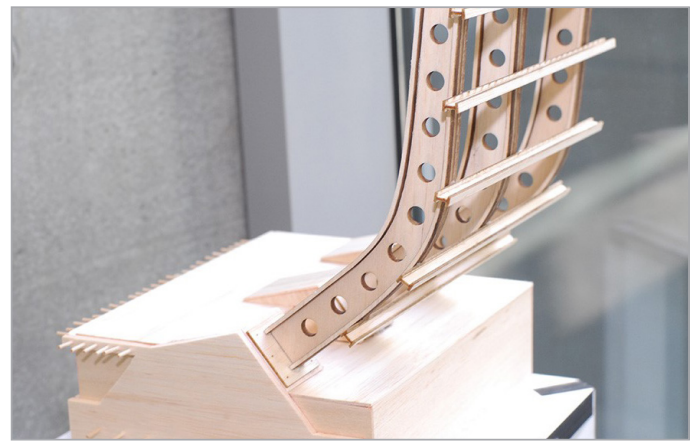

Fig. 2

Structural detail model in 1:20 scale laser-cut from $5 \mathrm{~mm}$ MDF material

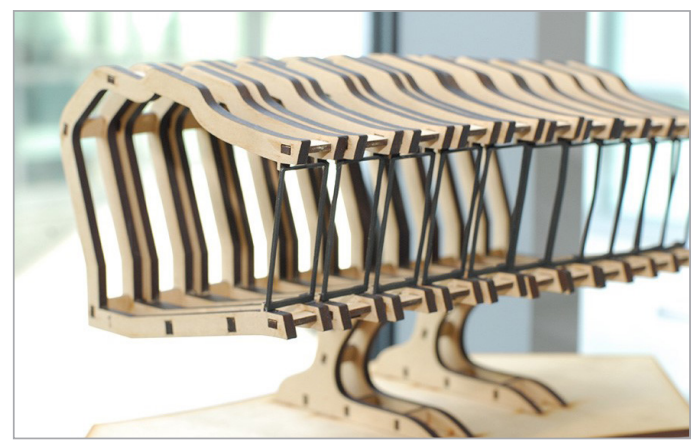

Fig. 3

Scale model of a church project in 1:200 with removable roof to reveal its interior architecture made of ABS-plastics on a Stratasys uPrint industrial level 3D printer

Fig. 4

Scale model of a kindergarten project in 1:200 made of ABS-

plastics on a Stratasys uPrint industrial level 3D printer
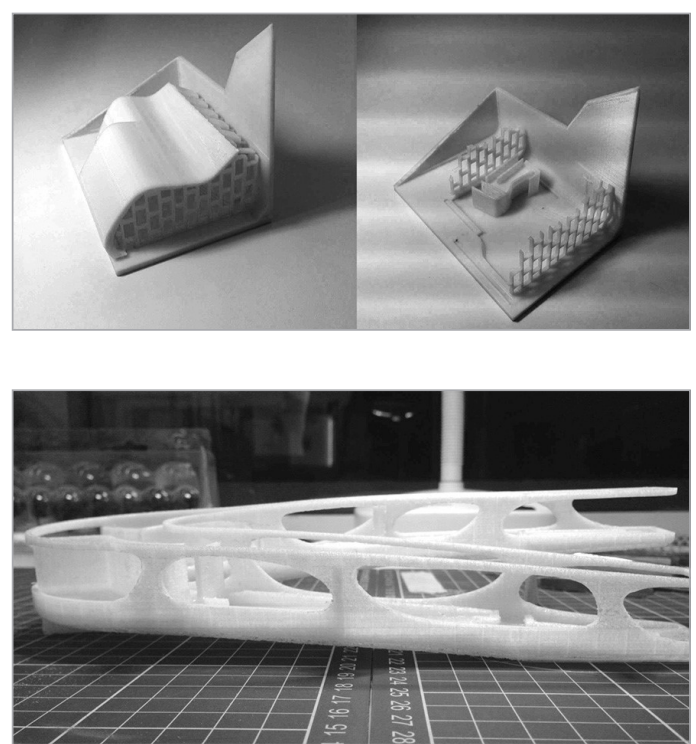

Fig. 5

Augmented Reality model of a juice bar interior project on an iPhone 6 running Augment application

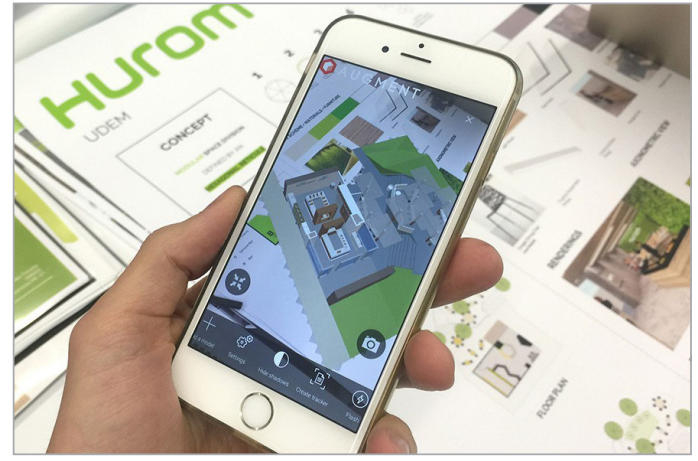

parts like window frames, stairs and even some small wall surface articulation could be reproduced. Industrial level 3D printers like the Stratasys uPrint can print from the actual model material that is very tough ABS-plastic and it can print an organic material that afterwards is being removed for supporting elements that have no base and that are floating in the air. To save the filling support material usage in the inside of the model volume for roof structures, those elements were printed separately thus allowing the models to be opened revealing their full architectural interiors.

From the two applications of model making in a design studio it was clear that any model making involves additional time, either for preparation of the model files for fabrication or actual assembly of the parts. The need of the models can be eliminated totally but that is an ongoing research as it depends from many factors like the reason for making model as a paradigm. Simplest and most straightforward method to save precious designing time and concentrate more on details is making virtual AR models. The method will probably never substitute physical scale models but it is widely applicable to short term projects and projects where many modifications need to be checked in almost real time. Author decided to check its potential applying AR model strategies in an interior design studio where the semester was divided into three distinct projects, each being made from scratch in 4-5 weeks time. As there is a very short learning curve to obtain a usable virtual representation of already existing 3D model, it was mainly small restrictions that needed special attention. For example, a 3D object contains too many polygons and therefore is too heavy for exporting or processing and various problems occurred with custom made textures that again reached the limits of being big file sizes that would take forever to post-process. In most cases the models were readily available for viewing on a handheld device just minutes after its upload and online processing (see Fig. 5). 
AR models do have additional features that physical models do not have and in reverse. The full comparison that is based on authors experience in two different studio setups is shown in Table 1, comparing all aspects from spatial representation qualities to related expenses.

The biggest risk is having an incomplete design strategy or having file errors, including wrongly modelled geometries. Especially 3D printing is less forgiving for errors like geometries not being closed solids or solids having inside-out orientation of their surface normals - the vectors which are perpendicularly oriented to its tangent plane of its surface, by default facing outwards. Another issue is the extra time needed for modeling to prepare files for physical 3D model fabrication. Often by reducing the scale there are elements that cannot be simply scaled down or need to be simplified in order to represent them well. There are also many limitations of the complex geometries to be made into physical models, this being one of the deciding factors for choosing model making strategy of an assembled model from various laser-cut parts or performing a full 3D print.

The industry of architecture in the future application of any model making is still very open for a continuous research of what is the very best way to get models done. New technologies are being made available in increasing speeds and therefore the experimentations in both physical and

\begin{tabular}{|c|c|c|}
\hline Feature & Physical scale models & Augmented Reality models \\
\hline Spatial sensation & $\begin{array}{l}\text { Great sense of volume or detail in its } \\
\text { complete volume }\end{array}$ & $\begin{array}{l}\text { Virtual immersion to fully explore the outside } \\
\text { or inside of a model }\end{array}$ \\
\hline Materiality & $\begin{array}{l}\text { Limited to chosen model material and } \\
\text { color }\end{array}$ & Full color, textures and lighting with shadows \\
\hline Detail level & $\begin{array}{l}\text { Details reduced to the resolution of the } \\
\text { chosen scale and fabrication method }\end{array}$ & Very accurate details in any scale \\
\hline Kinetics & Fixed model of one definite state & $\begin{array}{l}\text { Allows animation and movements of } \\
\text { elements (for ex., shades open/closed) }\end{array}$ \\
\hline Sense of scale & One chosen scale & $\begin{array}{l}\text { Full 1:1 scale, additional zooming or } \\
\text { magnification feature has a slight risk of } \\
\text { loosing sense of scale }\end{array}$ \\
\hline Handling & Handheld, fixed to a stand or boxed & $\begin{array}{l}\text { Fixed to a marker or space that gives mixed } \\
\text { sensation of its actual physical handling }\end{array}$ \\
\hline Creation time & $\begin{array}{l}\text { From several hours to days, } \\
\text { depending on fabrication method and } \\
\text { parts to be assembled }\end{array}$ & $\begin{array}{l}\text { Few minutes (conversion, exporting and } \\
\text { uploading to mobile devices) }\end{array}$ \\
\hline $\begin{array}{l}\text { Speed of } \\
\text { accessibility of the } \\
\text { model }\end{array}$ & $\begin{array}{l}\text { Physical model can be seen } \\
\text { immediately when it is reached by the } \\
\text { viewer }\end{array}$ & $\begin{array}{l}\text { AR model often involves downloading and } \\
\text { installing a specific application or loading the } \\
\text { model from a web browser (limitation is the } \\
\text { data speed and availability of internet) }\end{array}$ \\
\hline Mobility & $\begin{array}{l}\text { The size and weight are constraints } \\
\text { to face when transporting physical } \\
\text { models, also they can only be } \\
\text { exhibited in one location only }\end{array}$ & $\begin{array}{l}\text { Via e-mail or a download, can be copied and } \\
\text { seen simultaneously virtually anywhere } \\
\text { where the internet reaches or where you can } \\
\text { carry it as a previously downloaded file and } \\
\text { see it in a compact mobile device }\end{array}$ \\
\hline Updating model & $\begin{array}{l}\text { Usually involves making new model } \\
\text { or parts of a model }\end{array}$ & $\begin{array}{l}\text { Very flexible - any momentary design } \\
\text { changes can be updated during the workflow }\end{array}$ \\
\hline Related expenses & $\begin{array}{l}\text { Material, fabrication and assembly } \\
\text { labor totals depending on the size and } \\
\text { complexity }\end{array}$ & $\begin{array}{l}\text { Model cost very low, additionally the value of } \\
\text { the hand-held device }\end{array}$ \\
\hline
\end{tabular}

\section{Discussion}

\section{Table 1}

Features comparison of physical vs. Augmented Reality models 
virtual models need to be made in academic environments first, followed by application in design offices. To be prepared for the real life modeling situations future architects must have accumulated the expertise that makes presenting their design ideas as clear as possible.

\section{Conclusions}

After a more in-depth analysis of physical vs. AR models we can conclude that neither of the two methods does completely eliminate each other of the modeling methods, and in a perfect real-life application they rather can complement to showcase the best elements of any design from a broader point of view. There will always be intentions to replace or improve the given technologies and if possible also speed up the model assembly or processing times, cutting down the expenses and the material usage. Future profession of architects will still have to use any of the modeling techniques analysed in this article, cleverly choosing the best way to represent their projects to the clients. Therefore it is very important to integrate the prototyping and all possible virtual representation methods in the academic study projects so they can be learned in making actual designs. It has to be noted that any model making involves lot of time in specific 3D software and significant efforts in fine-tuning or detailing.

Acknow-

Prof. Dr. Marcelo Espinosa from University of Monterrey (UDEM), Mexico for sharing immense amount of details and attitude to the technical details in design and Javier Gomez Flores, technician of prototyping and digital fabrication laboratory at Center of Roberto Garza Sada of Art, Architecture and Design also from UDEM, for countless hours of help in mastering the industry leading prototyping machinery.

\section{References}

Badalge K. In world's first 3-D printed home community, houses will be built in a day for $\$ 4000$. Archdaily, 27 Mar. 2018, https://www.archdaily. com/891065/in-worlds-first-3d-printed-community-houses-cost-4000-dollars-and-are-built-in-24hours.

Drury C. World's first 3D-printed home unveiled in France. Independent, 11 Apr. 2018, https://www.independent.co.uk/news/world/europe/3d-printedhome-world-first-france-a8298446.html.

Starner T., Mann S., Rhodes B., Levine J., Healey J., Kirsch D., Picard R.W., Pentland A. Augmented reality through wearable computing. Presence: Teleoperators and Virtual Environments, 1997, 6(4): 386-398. https://doi.org/10.1162/pres.1997.6.4.386
Wagner D., Pintaric T., Ledermann F., Schmalstieg D. Towards massively multi-user augmented reality on handheld devices. In: Gellersen H.W., Want R., Schmidt A. (eds) Pervasive computing. Pervasive 2005. Lecture notes in computer science 3468. Berlin, Heidelberg: Springer; 2005.

Wheatstone R. World's first 3D printed house is completed after just 45 days in revolution for home building. Mirror, 27 Jun. 2016, https://www.mirror. co.uk/news/world-news/worlds-first-3d-printedhouse-8297190.

World's first 3D-printed bridge opens to cyclists in netherlands. The Guardian, 18 Oct. 2017, www. theguardian.com/technology/2017/oct/18/worldfirst-3d-printed-bridge-cyclists-netherlands.

\section{About the Author}

\section{DR. ARNE RIEKSTINS}

\section{Full Professor of Architecture}

University of Monterrey, Department of Art, Architecture and Design (DAAD)

\section{Main research area}

Digital and Parametric Architecture

\section{Address}

Av. Ignacio Morones Prieto 4500 Pte

66238 San Pedro Garza García

Nuevo Leon, Mexico

Tel. +52(81)8215-1450

E-mail: arne.riekstins@udem.edu 